\title{
Correction to: The Expansion of Irrigated Agriculture in Brazil and Potential Regional Limitations
}

\author{
Angel dos Santos Fachinelli Ferrarini, \\ Joaquim Bento de Souza Ferreira Filho, Santiago Vianna Cuadra, \\ Daniel de Castro Victoria and Mark Horridge
}

\section{Correction to:}

Chapter 7 in: G. Wittwer (ed.), Economy-Wide Modeling of Water at Regional and Global Scales, Advances in Applied General Equilibrium Modeling, https://doi.org/10.1007/978-981-13-6101-2_7

In the original version of the book, the following correction has been incorporated in Chapter 7.

The sequence of the authors has been changed from 'Santiago Vianna Cuadra, Daniel de Castro Victoria, Angel de Santos Fachinelli Ferrarini, Joaquim Bento de Souza Ferreira Filho and Mark Horridge' to 'Angel dos Santos Fachinelli Ferrarini, Joaquim Bento de Souza Ferreira Filho, Santiago Vianna Cuadra, Daniel de Castro Victoria and Mark Horridge'.

The correction chapter and the book have been updated with the change. 